Int. Agrophys., 2019, 33, 241-253

\title{
Simulating the partitioning of winter rape biomass by increasing the cutting height of stems**
}

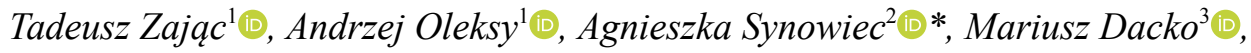 \\ Agnieszka Klimek-Kopyra ${ }^{1}$, Karolina Ratajczak ${ }^{4}$, and Bogdan Kulig ${ }^{1}$
${ }^{1}$ Department of Crop Production, Institute of Plant Production, ${ }^{2}$ Department of Agrotechnology and Agricultural Ecology, ${ }^{3}$ Department of Agricultural Economics and Organisation, Institute of Economic and Social Science; University of Agriculture, Al. Mickiewicza 21, 31-120 Kraków, Poland
${ }^{4}$ Department of Agronomy, Faculty of Agronomy and Bioengineering, Poznań University of Life Sciences, Dojazd 1, 60-632 Poznań, Poland

Received June 14, 2018; accepted December 11, 2018

\begin{abstract}
In three seasons 2010-2013, field experiments with two hybrid cultivars of winter oilseed rape were conducted in three localities in Southern Poland, with the aim of assessing changes in the harvest index, as compared to the agricultural harvest index of winter oilseed rape, defined as the harvest index decreased by the stubble height in relation to three plant categories (small, medium and large). As a result, an increase in the height of the stubble of winter oilseed rape in the range of $0-60 \mathrm{~cm}$ led to an increase in the agricultural harvest index value by about 0.081 for cv. 'Adam', and by 0.078 for cv. 'Poznaniak'. The agricultural harvest index values were changed mostly by the vegetative seasons $(p<0.001)$. An increase in the height of the stubble of winter oilseed rape by $10 \mathrm{~cm}$ increased the agricultural harvest index of small, medium and large plants by about 0.091 , 0.075 and 0.073 , respectively, as compared to the harvest index values. The linear correlation between the height of the stubble of the winter oilseed rape plants and their agricultural harvest index was significant $\left(\mathrm{R}^{2}=0.97-0.99\right)$. Depending on the factor (cultivar, locality, vegetative season or plant category), an increase in the height of the stubble of winter oilseed rape by $10 \mathrm{~cm}$ contributed to an improvement in agricultural harvest index from 0.012 to $0.015 \mathrm{~g} \mathrm{~g}^{-1}$.

Keywords: agricultural harvest index, harvest index, stem diameter, stubble mass, yield
\end{abstract}

\section{INTRODUCTION}

Brassicas species, i.e. Brassica napus; B. rapa; B. jun$c e a$ and $B$. carinata are given a common name 'rapeseed' or 'oilseed rape' (Berry and Spink, 2006). Presently, Brassica

*Corresponding author e-mail: a.stoklosa@ur.krakow.pl

**This work was financed by the National Science Center grant No N310 169139, realised in years 2010-2013. napus L. var. oleifera subvar. biennis or annua is a leading crop in the group of 'oilseed rape'. In warmer and cooler zones of the temperate European climate, the winter form of oilseed rape is the most popular because of its higher yielding, as compared to the spring form (Peltonen-Sainio and Jauhiainen, 2008; Waalen et al., 2013). According to FAOSTAT data (FAOSTAT, 2016), the area of winter oilseed rape (WOR) cultivation is constantly expanding in global terms, advancing from the fourth position in the past to the third most sought oil-crop, following soybean and palm oil. The global average yield of WOR doubled between 1970 and 2009, increasing from ca. 800 to $1900 \mathrm{~kg}$ $\mathrm{ha}^{-1}$, with an increase rate of ca. $27 \mathrm{~kg} \mathrm{ha}^{-1} \mathrm{y}^{-1}$ for the whole period in question (Rondanini et al., 2012). Between 2000 and 2015, there was an impressive increase in the yield of WOR in Poland; in this time interval, the annual increase in the yield of about $84 \mathrm{~kg} \mathrm{ha}^{-1} \mathrm{y}^{-1}$ was achieved (FAOSTAT, 2016), as a result of the common introduction of hybrid cultivars of WOR. As predicted, that increase in the yield of WOR will promote an increase in the growing area of WOR, both in temperate, and in warmer and dryer climates (Zając et al., 2016).

The harvest index (HI) provides information about the share of the seed yield (the harvested yield) in the total aboveground dry mass of the crop (expressed in $\mathrm{g} \mathrm{g}^{-1}$ ) (Donald and Hamblin, 1976). Hay (1995) applied HI to compare

(C) 2019 Institute of Agrophysics, Polish Academy of Sciences 
several agricultural crops. At the same time, this author pointed to a significant disparity of information regarding HI in particular crop species, including WOR (Hay, 1995).

The HI values of WOR are labile between vegetative seasons and climates. Data for the HI values of WOR, calculated by Greef et al. (1993), are in the range of 0.25 $0.30 \mathrm{~g} \mathrm{~g}^{-1}$. Huehn (1993) assessed the HI values for the WOR cultivars grown in the north of Germany (SchleswigHolstein) in the range from 0.22 to $0.34 \mathrm{~g} \mathrm{~g}^{-1}$. The highest HI values of WOR were recorded in Germany $0.53 \mathrm{~g} \mathrm{~g}^{-1}$ (Rathke et al., 2005; Schulte auf 'm Erley et al., 2011). WOR $c v$. 'Apex' grown in Central England had the HI values of 0.26-0.3 $\mathrm{g} \mathrm{g} \mathrm{g}^{-1}$ (Scott et al., 1999). Habekotte (1997) who compared the growth and productivity of WOR plants grown in six localities within the Atlantic climatic zone received a HI value of $0.342 \mathrm{~g} \mathrm{~g}^{-1}$. Miri (2007) and Ghassemi-Golezani et al. (2010) underline that WOR cultivars in the arid climate have $\mathrm{HI}$ values of around $0.4 \mathrm{~g} \mathrm{~g}^{-1}$. On the other hand, the HI value of the spring cultivars of oilseed rape in arid climate is low, in the range of 0.2-0.3 (Gunasekera et al., 2006; Kazemeini et al., 2010; Özer et al., 1999; Rad et al., 2014; Taheri et al., 2012). Similar values of HI were recorded in China, where they were correlated with the time of WOR ripening. Namely, the middleripened cultivars had better HI values, as compared to the early- and late-ripened cultivars, but their $\mathrm{HI}$ was not higher than $0.3 \mathrm{~g} \mathrm{~g}^{-1}$, due to high plants of (Yuan and Guan, 1998).

In recent years intensive cultivation of WOR has resulted in the introduction of hybrid cultivars (Luo et al., 2015.) of a lowered plant density per unit area of 30-40 germinating seeds per $1 \mathrm{~m}^{2}$. Hybrid cultivars of WOR develop huge plants of favorable HI, due to a large number of siliques per plant (Koeslin-Findeklee and Horst 2016; Kuai et al., 2015). Sieling and Kage (2008) compared the productivity of four hybrid WOR cultivars whose HI was similar, in the range of $0.38-0.40 \mathrm{~g} \mathrm{~g}^{-1}$. In contrast, the recently bred semi-dwarf WOR cultivars have shown lower HI values, as compared to the hybrid ones (Jankowski et al., 2016).

The combine harvesting of WOR, observed recently in Central Europe, leaves a high stubble $(30-40 \mathrm{~cm})$ in the field. For this reason, in this work we propose a new parameter, called agricultural harvest index (AHI), which, in contrast to HI, excludes the stubble of WOR from the calculations, due to the cutting height. It can be assumed that the height of the stubble of WOR after harvest will significantly change the AHI value. In scientific literature, information about the height of the stubble is given very rarely. Namely, Mazhari et al. (2013) notes that in Iran WOR plants were low hand-cut at 2-4 $\mathrm{cm}$ above the ground level, as the stem was further utilized for paper production. Moreover, there is no data on the diameter of the WOR stem in its lower parts. It is underlined that a higher HI for cereals was obtained by the shortening of the cereals stem (Acquaah, 2005). We hypothesize that a similar effect might be acquired in WOR plants, due to an increased height of the stubble, which leads to higher amounts of biomass left in the field, on the one hand, and higher AHI values, on the other. For that reason, this work aimed at assessing changes in the AHI values of the hybrid cultivars of WOR of different plant categories (small, medium and large), in relation to the simulation of different heights of the stubble.

\section{MATERIAL AND METHODS}

Field experiments were carried out during three seasons 2010-2013 and were located in three Research Centers in Southern Poland, i.e. Głubczyce $\left(17^{\circ} 50^{\prime} \mathrm{E}, 50^{\circ} 12^{\prime} \mathrm{N}\right)$, Pawłowice $\left(18^{\circ} 31^{\prime} \mathrm{E}, 50^{\circ} 28^{\prime} \mathrm{N}\right)$ and Prusy $\left(20^{\circ} 05^{\prime} \mathrm{E}, 50^{\circ}\right.$ $\left.07^{\prime} \mathrm{N}\right)$. All the three centers are located along a similar north latitude. In Głubczyce and Prusy the experiments were set up on a degraded Chernozem, situated on loess, while in Pawłowice the experimental field was set on the Luvisols formed from glacial till.

A method of valorization of the agricultural production area (VAPA) (Witek et al., 1994), was applied to the studied localities, in order to evaluate the overall conditions of agricultural production, based on four indicators, i.e. soil quality, relief, agroclimatic conditions and water relations. There is a range of summary-points in the VAPA method, where 20 is the minimum and 122 the maximum. The summary-points calculated for the three localities were as follows: Prusy - VAPA 102, Głubczyce - VAPA 94, and Pawłowice - VAPA 65, which accounted for 85, 78 and $54 \%$ of the maximum VAPA summary-point, respectively.

The experiments were set up in a split-plot design, with three replications. The size of a single plot for harvest was $10 \mathrm{~m}^{2}$ in Prusy, and $16.5 \mathrm{~m}^{2}$ in Głubczyce and Pawłowice. The space between individual rows in Glubczyce and Pawłowice was $30 \mathrm{~cm}$, and in Prusy $28 \mathrm{~cm}$, with five rows per plot.

Two hybrid cultivars (F1) of winter oilseed rape (WOR), i.e. 'Adam' (AG Deutsche Saatveredelung) and 'Poznaniak' (Strzelce Plant Breeding Ltd. IHAR Group), were tested in this experiment. The terms of sowing/harvesting, plant densities and soil concentrations of major nutrients, as well as the main agrotechnical data are presented in Table 1.

In the growth phases of WOR, with the end of flowering - fruit development (BBCH 69-71), the number of plants was determined on two two-meters-long rows on each plot, and their production category, based on the number of lateral branches: small -1 to 4 , medium -5 to 7 and large $\geq 8$ branches, was assessed. Then, the percentage share of the plants of each production category per $1 \mathrm{~m}^{2}$ was calculated, based on which a representative sample of 10 plants was chosen and labeled with different colors: small - red, medium - green and large - blue. One week before combine harvesting, all the labeled plants from each plot were collected for detailed measurements at $\mathrm{BBCH}$ 83-85. The plants were cut at the ground level $(0 \mathrm{~cm})$. 
Table 1. Basic agrotechnical data for the localities of experiments

\begin{tabular}{|c|c|c|c|c|}
\hline \multirow{2}{*}{ Specification } & \multirow{2}{*}{$\begin{array}{l}\text { Vegetative } \\
\text { season }\end{array}$} & \multicolumn{3}{|c|}{ Locality } \\
\hline & & Głubczyce & Pawłowice & Prusy \\
\hline Forecrop & $\begin{array}{l}2010 / 2011 \\
2011 / 2012 \\
2012 / 2013\end{array}$ & Winter wheat & Winter wheat & $\begin{array}{l}\text { Winter wheat } \\
\text { Oats } \\
\text { Winter wheat }\end{array}$ \\
\hline Plant density (seeds $\mathrm{m}^{-2}$ ) & & & 60 & \\
\hline Sowing dates & $\begin{array}{l}2010 / 2011 \\
2011 / 2012 \\
2012 / 2013\end{array}$ & $\begin{array}{l}\text { Aug 26th } 2010 \\
\text { Aug 29th } 2011 \\
\text { Aug 22th } 2012\end{array}$ & $\begin{array}{l}\text { Sep 4th } 2010 \\
\text { Aug 23th } 2011 \\
\text { Aug 29th } 2012\end{array}$ & $\begin{array}{l}\text { Aug 26th } 2010 \\
\text { Aug 29th } 2011 \\
\text { Aug 28th } 2012\end{array}$ \\
\hline Harvest dates & $\begin{array}{l}2010 / 2011 \\
2011 / 2012 \\
2012 / 2013\end{array}$ & $\begin{array}{l}\text { Jul 19th } 2011 \\
\text { Jul 20th } 2012 \\
\text { Jul 29th } 2013\end{array}$ & $\begin{array}{l}\text { Jul 29th } 2011 \\
\text { Jul 13th } 2012 \\
\text { Jul 27th } 2013\end{array}$ & $\begin{array}{l}\text { Aug 2nd } 2011 \\
\text { Jul 19th } 2012 \\
\text { Jul 30th } 2013\end{array}$ \\
\hline $\begin{array}{l}\text { Levels of fertilizers } \\
\mathrm{N}: \mathrm{P}: \mathrm{K}: \mathrm{S} \\
\left(\mathrm{kg} \mathrm{ha}^{-1}\right)\end{array}$ & $\begin{array}{l}2010 / 2011 \\
2011 / 2012 \\
2012 / 2013\end{array}$ & $\begin{array}{l}215: 68: 125: 42 \\
185: 75: 150: 35 \\
220: 50: 150: 45\end{array}$ & $\begin{array}{l}215: 54: 114: 56 \\
172: 36: 116: 84 \\
167: 54: 114: 51\end{array}$ & $\begin{array}{l}200: 100: 181: 70 \\
200: 100: 181: 70 \\
200: 100: 181: 70\end{array}$ \\
\hline $\begin{array}{l}\text { Soil: } \mathrm{P}: \mathrm{K}: \mathrm{Mg} \\
\text { (mg } 100 \mathrm{~g}^{-1} \text { soil) }\end{array}$ & $\begin{array}{l}2010 / 2011 \\
2011 / 2012 \\
2012 / 2013\end{array}$ & $\begin{array}{l}25.0: 19.4: 15.3 \\
25.3: 30.0: 12.8 \\
24.5: 18.4: 15.2\end{array}$ & $\begin{array}{c}19.2: 20.7: 11.5 \\
19.9: 14.8: 11.7 \\
16.7: 21.6: 7.7\end{array}$ & $\begin{array}{l}14.6: 13.8: 14.2 \\
13.8: 12.5: 13.8 \\
17.1: 13.5: 14.2\end{array}$ \\
\hline $\mathrm{pH}$ & $\begin{array}{l}2010 / 2011 \\
2011 / 2012 \\
2012 / 2013\end{array}$ & $\begin{array}{l}6.5 \\
6.4 \\
6.2\end{array}$ & $\begin{array}{l}6.2 \\
6.1 \\
5.7\end{array}$ & $\begin{array}{l}6.2 \\
6.1 \\
6.1\end{array}$ \\
\hline $\begin{array}{l}\text { Herbicides } \\
\text { (active ingredient) }\end{array}$ & $2010-2013$ & $\begin{array}{l}\text { metazachlor, } \\
\text { chinomerac, } \\
\text { quizalofop-P-ethyl }\end{array}$ & metazachlor, chinomerac & $\begin{array}{l}\text { metazachlor, } \\
\text { chinomerac, } \\
\text { fluazifop-P-butyl, } \\
\text { chlopyralid, picloram }\end{array}$ \\
\hline $\begin{array}{l}\text { Insecticides } \\
\text { (active ingredient) }\end{array}$ & $2010-2013$ & $\begin{array}{l}\text { deltametrine, } \\
\text { chloropiryphos, } \\
\text { cynalotrine, } \\
\text { 1,2-benzizothiazole }\end{array}$ & $\begin{array}{l}\text { zeta-cypermetrine, } \\
\text { deltametrine, } \\
\text { acetampiride }\end{array}$ & $\begin{array}{l}\text { acetampiride, } \\
\text { metkonazole, } \\
\text { bifentrine }\end{array}$ \\
\hline $\begin{array}{l}\text { Dessicant } \\
\text { (active ingredient) }\end{array}$ & $2010-2013$ & diquat & - & glufosinate \\
\hline
\end{tabular}

The length of the cut plants was measured, and then they were placed separately in the polypropylene bags to dry and to avoid seed losses. Bags with plants were dried under natural conditions, in darkness, in a ventilated barn for 1 month.

The air-dry plants were weighed separately, and then the lower part of the stem was cut off at a height of $60 \mathrm{~cm}$. The stem was then cut into $10 \mathrm{~cm}$ long pieces. The obtained sections were weighed, and a diameter of their part was measured individually by electronic calipers Yato ${ }^{\circledR}$. The obtained six sections were then put together into a separate box.

The other part of each plant was placed in another box and carefully hand-threshed to receive all the seeds. The seeds were then sieved and placed in cotton bags. All the vegetative parts of the plants that were left were cut into $5 \mathrm{~cm}$ pieces and also placed in separate cotton bags.
All the collected parts of the plants were dried in a ventilated dryer in a temperature of $72^{\circ} \mathrm{C}$ for $48 \mathrm{~h}$. After drying, the samples were weighed and their aerial dry matter was re-calculated for $9 \%$ of water content, according to Berry and Spink (2006).

Then, the harvest index (HI) was calculated for the zero cutting height, using the formula given by Donald and Hamblin (1976):

$$
\mathrm{HI}=\frac{\text { seed yield }}{\text { biological yield }},
$$

where: seed and biological yield $\left(\mathrm{g} \mathrm{plant}^{-1}\right),\left(\mathrm{g} \mathrm{g}^{-1}\right)$.

Also, a new quotient parameter, called the agricultural harvest index (AHI), was calculated for the six simulated cutting heights:

$$
\mathrm{AHI}=\frac{\text { seed yield }}{\text { biological yield }- \text { stubble yield }},
$$

where: stubble yield $\left(\mathrm{g} \mathrm{plant}^{-1}\right),\left(\mathrm{g} \mathrm{g}^{-1}\right)$. 
Based on the detailed data (plant density per $\mathrm{m}^{-2}$ and the mass of the individual stems), the absolute dry mass of the stubble that could be left in the field was calculated.

Based on the regression calculation, the co-linearity between the HI, AHI and the simulated height of the stubble of WOR at harvest time was analyzed, using the following equation:

$$
y=\alpha+\beta x,
$$

where: $x$ - height of stubble of WOR, $y$-AHI (agricultural harvest index), $\alpha$-intercept, $\beta$ - regression coefficient.

Model parameters $(\alpha, \beta)$ were estimated using the least squares method, a typical method used for estimating and determining trend lines based on a set of data in pairs (Chavent, 1979).

The direction coefficient in the regression equations $(\beta)$ allowed a direct assessment of the impact strength of changing the cutting height by one unit on the change in the AHI parameter. The intercept $(\alpha)$ reflected the HI (harvest index) value at a soil surface level (control).

The yield and morphological data were analyzed using Statistica ${ }^{\circledR}$ ver. 12 (StatSoft PL) by one or two-way analysis of variance in the General Linear Models Package. The significance of differences between mean values was determined by Fisher post-hoc test.
Weather conditions were expressed as the hydrothermal index $\mathrm{K}$, which combines both precipitation and air temperature above $0^{\circ} \mathrm{C}$, according to the following formula (Skowera et al., 2014):

$$
\mathrm{K}=\frac{P}{0.1 \Sigma t},
$$

where: $P$ is the sum of the monthly precipitation, and $\Sigma t$ is the sum of daily mean temperatures $>0^{\circ} \mathrm{C}$.

Indices $\mathrm{K}$ were calculated for the spring-summer (April-July) vegetative season of WOR, based on the daily temperature and precipitation records from the meteorological stations near each of the experimental stations.

Based on the demand of WOR for water in Lower Silesia, both water excess and shortages were calculated in the spring months of vegetation, i.e. from April to June, based on Dzieżyc et al. (2013).

The hydrothermal conditions were different for each of the experimental sites (Table 2). The optimal conditions for the growth of WOR occurred in April-July 2012 in Pawłowice and Prusy. The most humid conditions prevailed in Prusy, whereas in Pawłowice and Głubczyce the periods of April-July in 2011 and 2012, respectively, were relatively dry. July 2011 was extremely humid; in that month there was a visible excess of rainfalls, especially in

Table 2. Weather conditions, hydrothermal index $\mathrm{K}$ and excess/shortages of water for oilseed rape in the vegetative seasons 2010 2013 in the three studied localities

\begin{tabular}{llll}
\hline Vegetative season & & Locality & \\
\cline { 2 - 3 } & Głubczyce & Pawłowice & Prusy \\
\hline
\end{tabular}

Hydrothermal index K (Skowera et al., 2014)

$2010 / 2011$

$2011 / 2012$

$2012 / 2013$

$2010 / 2011$

$2011 / 2012$

$2012 / 2013$

$2010 / 2011$

$2011 / 2012$

$2012 / 2013$
1.9 (relatively humid)

1.3 (relatively dry)

1.6 (optimal)
1.27 (relatively dry)

1.50 (optimal)

1.67 (relatively humid)
2.1 (humid)

1.6 (optimal)

2.0 (relatively humid)

Sum of precipitation (mm) April-July

347.8

238.6

284.7

15.0

15.0

14.9
232.5

232.4

306.4

Mean air temperature $\left({ }^{\circ} \mathrm{C}\right)$ April-July

15.0

12.6

15.0
377.5

304.4

359.2

15.1

15.7

15.0

Excess/shortage (+/-) of water in relation to the optimal conditions (Dzieżyc et al., 2013)

April May June April May

$+21 \quad-4 \quad+57$

$2011 / 2012$

$2012 / 2013$ $\begin{array}{lllll}+45 & -45 & +29 & +61 & -38\end{array}$

$\begin{array}{lllll}+9 & +56 & +92 & +5 & +59\end{array}$

\begin{abstract}
June
\end{abstract}
$+16$

$+44$

$+95$
April

$+66$

$+58$

$+8$
May June

$-12+17$

$-50+116$

$+20 \quad+186$


Głubczyce and Prusy, which prolonged the harvest time of WOR. In 2013, the humidity during two months, namely May and June, exceeded WOR requirements (Table 2). The results were analyzed using one-way analysis of variance in STATISTICA PL software ver.13.3 (Dell Inc.). Means were separated by Tukey test. Also, the linear regression equations were calculated to assess the level of interdependence between the tested traits.

\section{RESULTS}

The WOR cultivars ('Adam' and 'Poznaniak') by the end of their vegetation were of a similar height and mass of both plants and seeds (Fig. 1). On the other hand, the weather conditions in different vegetative seasons significantly affected both the height and the biomass of plants and seeds. In the season 2011/2012, which was quite humid, a single plant produced a significantly higher biomass ( $c a .70 \mathrm{~g}$ ), which was correlated with the plant height. The factor that significantly influenced the height of a single WOR plant was also the locality; in Głubczyce (VAPA 94) plants were the highest and in Prusy (VAPA 102) the lowest (Fig. 1).
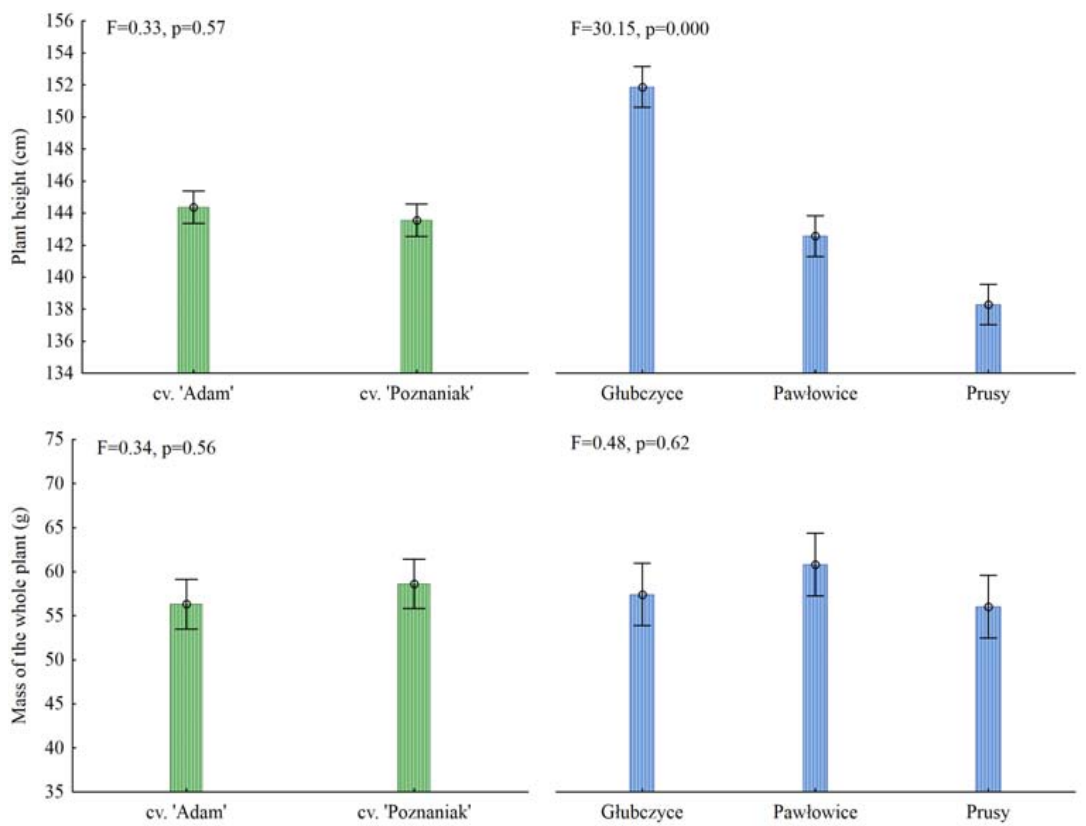

$F=0.48, p=0.62$
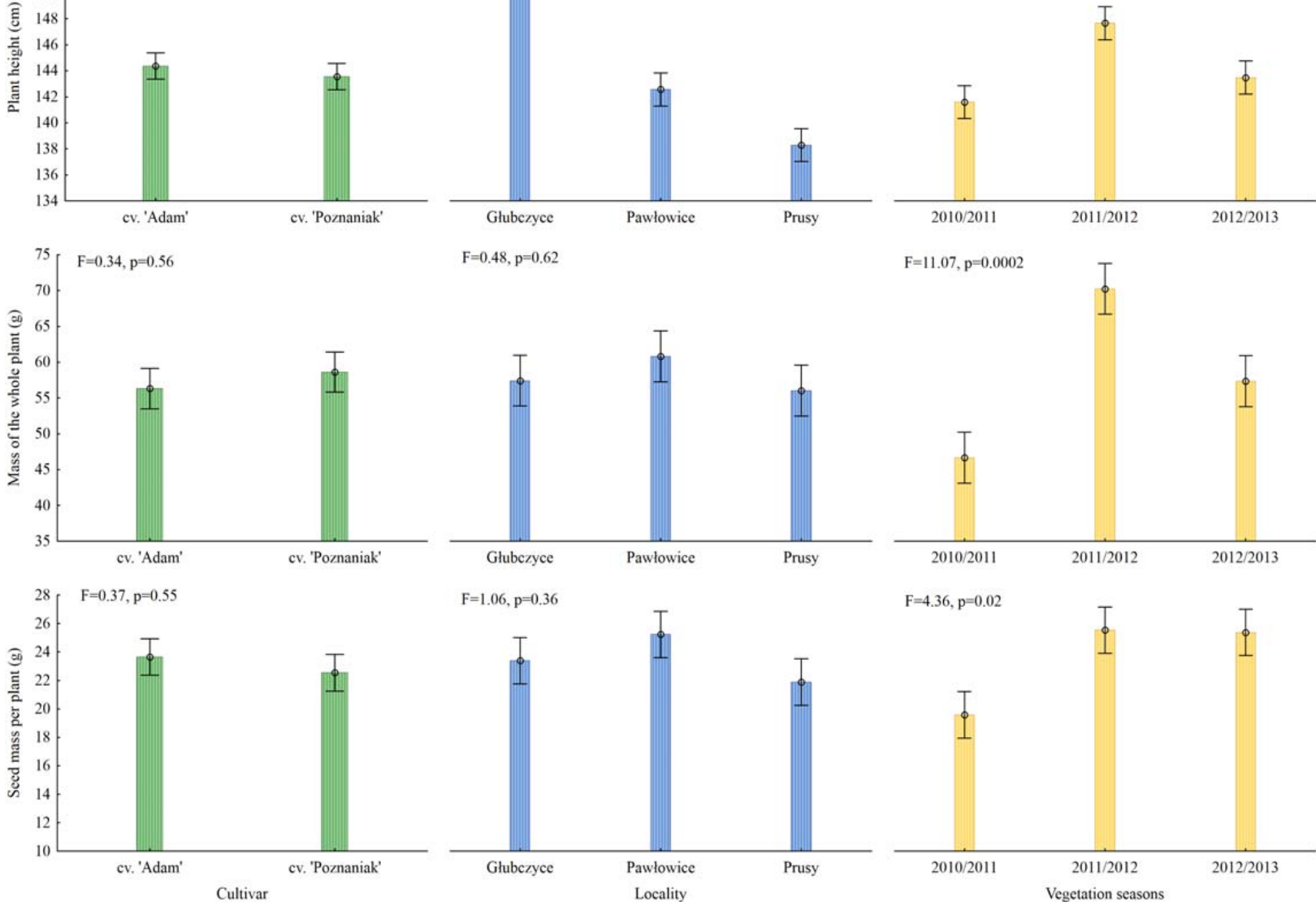

$\mathrm{F}=1.06, \mathrm{p}=0.36$

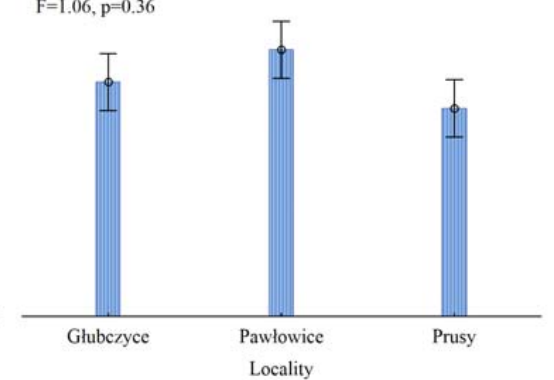

The lower sections of the main stem $(0-60 \mathrm{~cm})$ of the selected categories of WOR plants differed in the height of branching. Lower WOR plants, collected from Prusy, branched at a lower height, as compared to plants collected from the other localities (Fig. 2).

A detailed analysis of the dry mass of the $10 \mathrm{~cm}$ sections of the main stem showed that the lowest 0-10 cm section, measured from the soil surface, was of the highest dry mass (Fig. 3). The share of the mass of this section $(0-10 \mathrm{~cm})$ in the total mass of the bottom part of the main stem $(0-60 \mathrm{~cm})$ was $25-29 \%$. As the cutting height increased, the mass of the main shoot sections decreased. In each case, the mass of the highest section, i.e. $50-60 \mathrm{~cm}$, differed significantly from the mass of each of the two lowest sections (Fig. 3).

It was also found that the average weight of the sections of the main shoot in both the WOR cultivars, as well as for the localities and the vegetative seasons, was similar (Fig. 3A). In turn, the dry mass of the main stem of the plants of different categories was significantly affected (Fig. 3D). Particularly massive sections were found in large
$\mathrm{F}=5.99, \mathrm{p}=0.006$ 


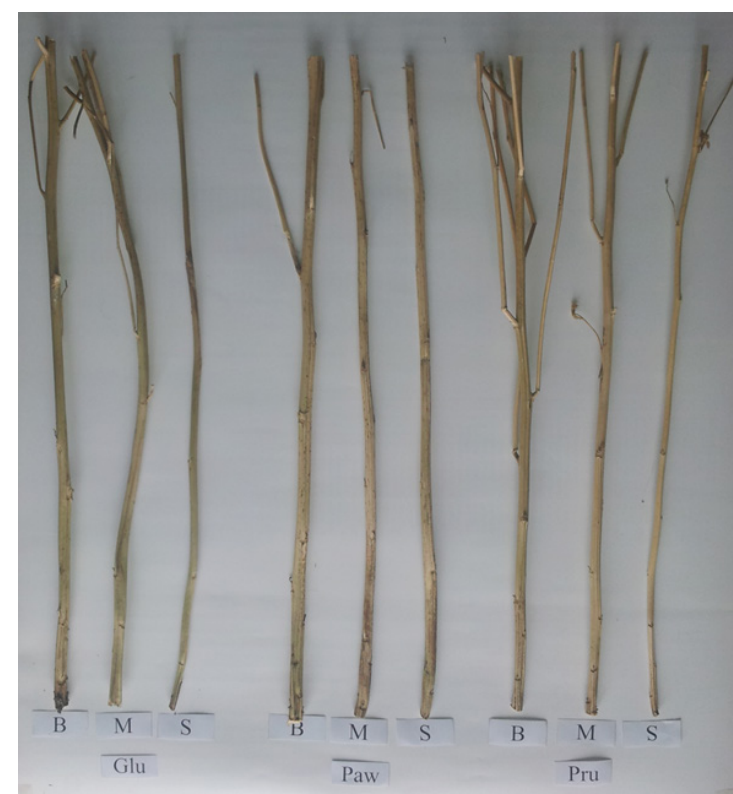

Fig. 2. Lower sections of the main stem $(0-60 \mathrm{~cm})$ of the selected categories of winter oilseed rape plants from the different localities and of different categories. Głubczyce (Glu), Pawłowice (Paw), Prusy (Pru), large (B), medium (M), small (S).
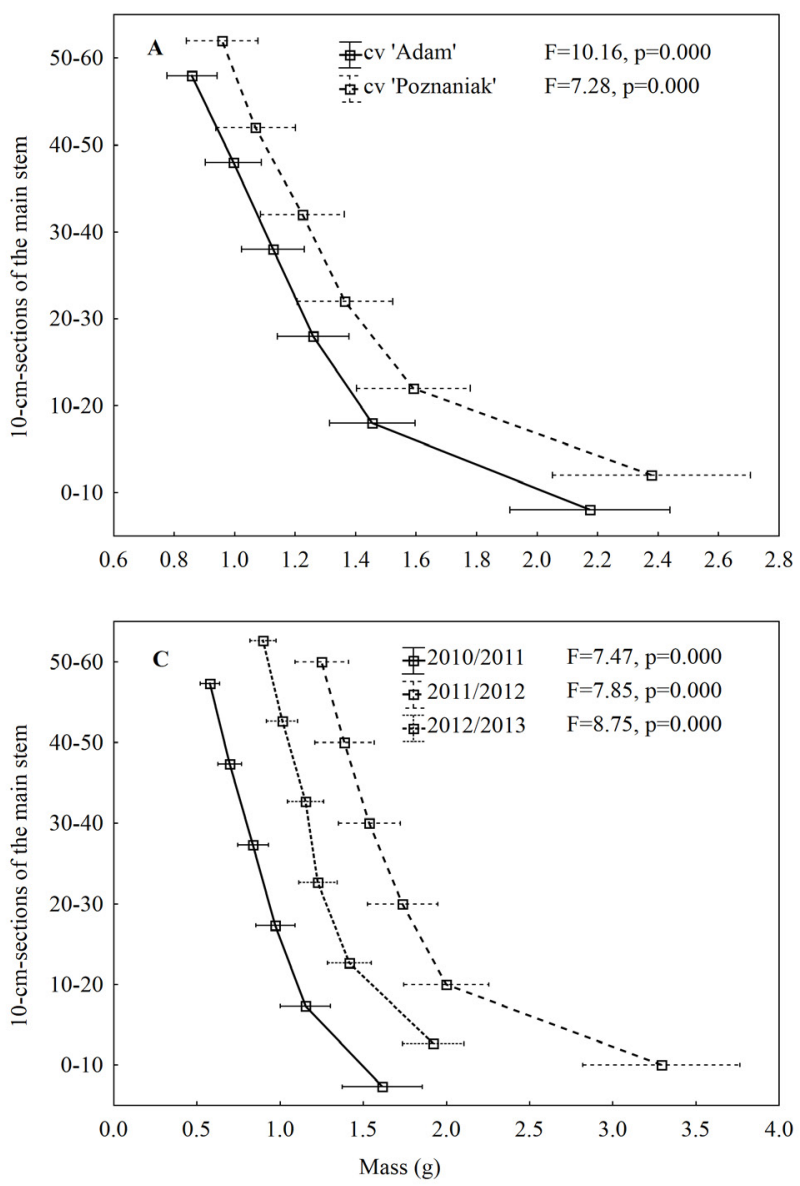

plants. On the other hand, the mass of the sections of small plants was significantly lower and oscillated in the range of 1.2-0.6 $\mathrm{g}$ of dry matter.

The diameter of $10 \mathrm{~cm}$ sections of the main stem, measured in the middle of their length, largely correlated with the trends observed for the mass of these sections. The diameter of the middle part of the subsequent sections decreased when moving upward (Fig. 4). In the lowest section $(0-10 \mathrm{~cm})$, the diameter of the stem was the largest.

As in the case of the mass of sections, a similar diameter of individual sections was found for both WOR varieties and localities. Significant differences in the diameter of the sections were shown for vegetative seasons (Fig. 4C). Under the optimal hydrothermal conditions of the season $2011 / 2012$, the diameter of the stem sections was significantly higher than in the other two vegetative seasons. Significant differences in the diameter of the plant sections also appeared in the case of the plant category where, similarly as in the case of biomass, the larger diameter of the sections, the larger the plants (Fig. 4D).

The empirical data showed changes in the agricultural harvest index (AHI) value of WOR, as a result of an increased height of the stubble, with intervals of $10 \mathrm{~cm}$
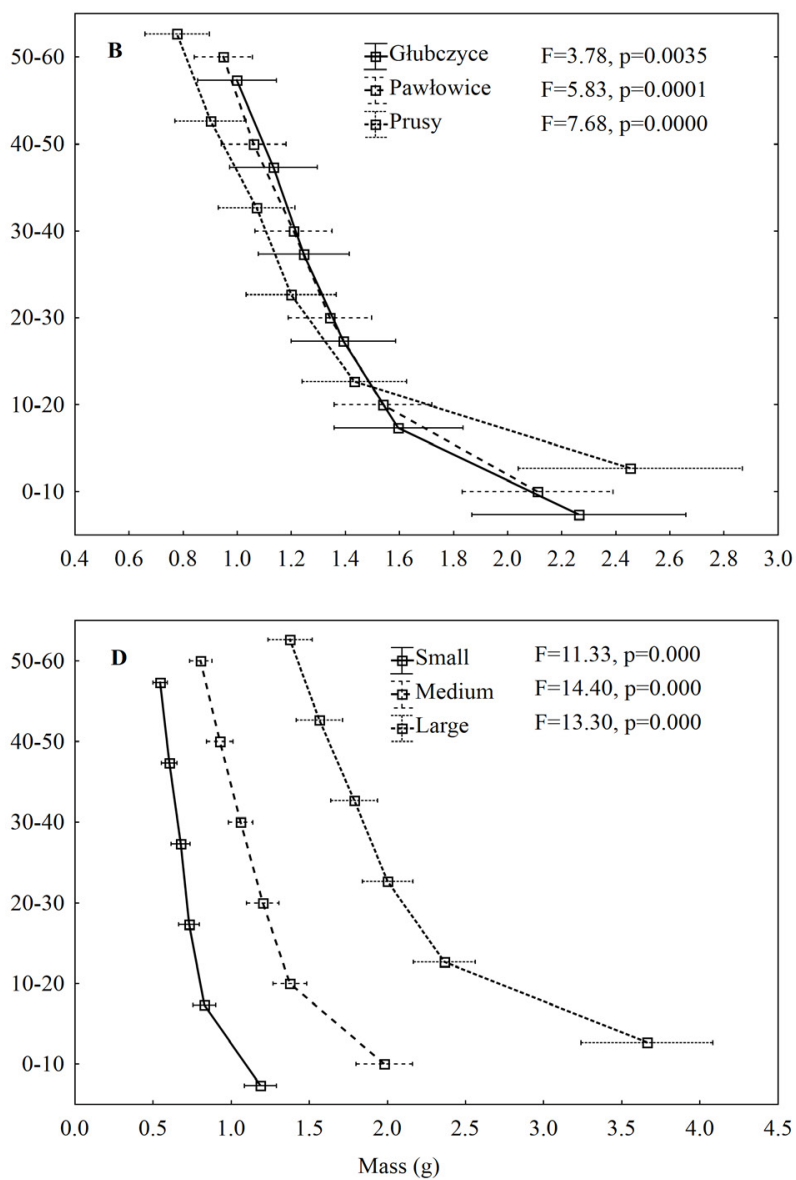

Fig. 3. Changes in the dry mass of $10 \mathrm{~cm}$ sections of the main stem of winter oilseed rape (g) for different: A - cultivars, B - localities, $\mathrm{C}$ - vegetative seasons, and D - plant categories. A one-way analysis of variance, with vertical bars representing \pm standard error. 

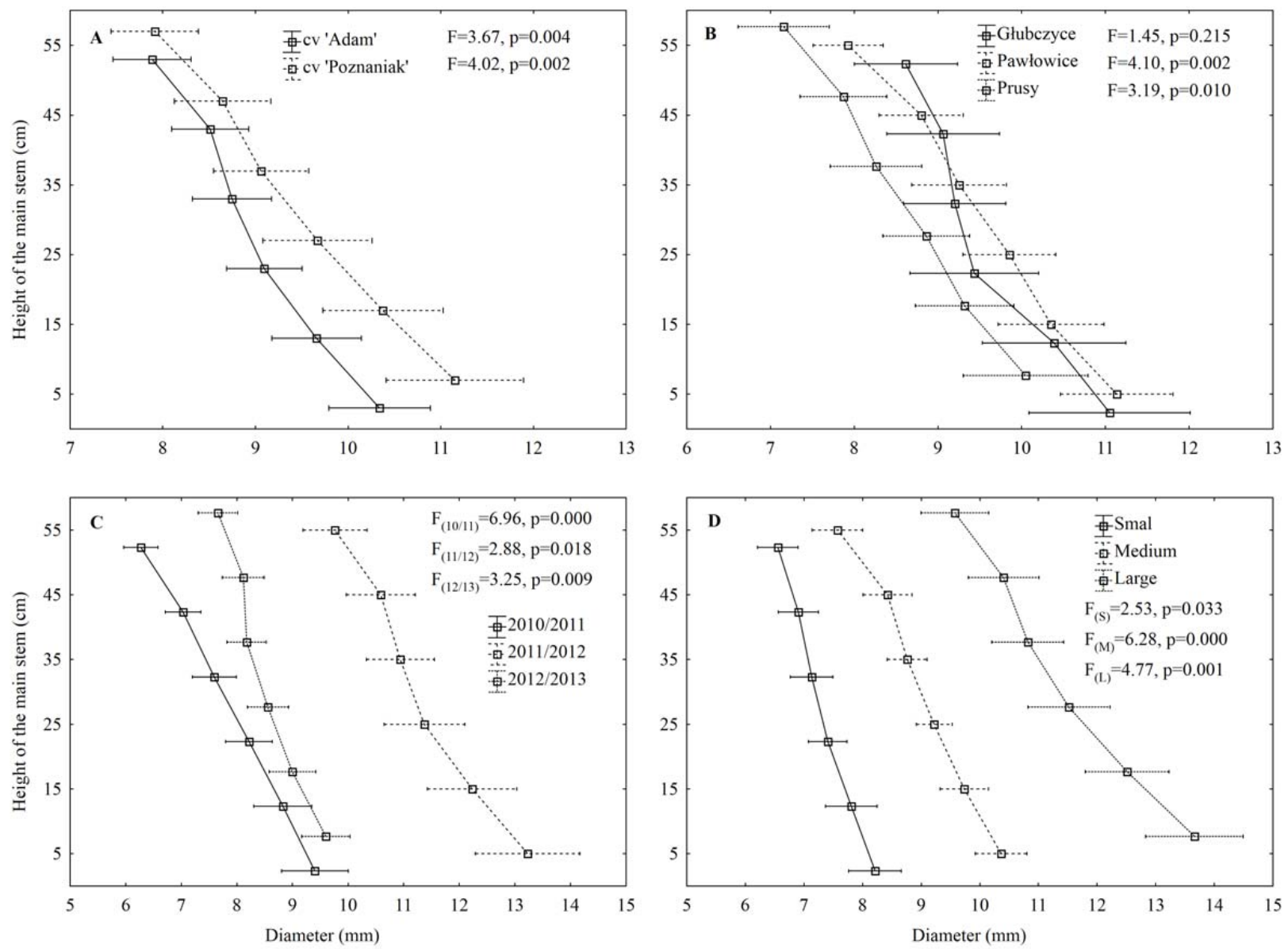

Fig. 4. Changes in the diameter of the main stem of winter oilseed rape (g) at a height of $5,15,25,35,45$ and $55 \mathrm{~cm}$, for different: A - cultivars, B - localities, C - vegetative seasons, and D - plant categories. A one-way analysis of variance, with vertical bars representing \pm standard error.

(Table 3). A comparison of the AHI values of WOR cultivars varied significantly; each time $c v$. 'Adam' showed significantly higher AHI values than $c v$. 'Poznaniak'. Low AHI variations for both cultivars were noted at lower stubble heights, and more variations occurred when cutting the stem at more than $20 \mathrm{~cm}$ above the ground level. Within the three localities, the most favorable AHI $>0.4$ was obtained in Pawłowice (VAPA 65), which was a result of the optimal growth of WOR plants which were of an average height but of a high individual yielding potential (Fig. 2B). Interestingly, there were no significant differences in AHI between the categories of WOR. Nevertheless, plants of the 'large' category always had a higher AHI value, as compared to plants of the 'small' category (Table 3).

The relationship between the cutting height of WOR, in the range of 10-60 cm, and changes in AHI was linear (Fig. 5). The interdependence between this pair of features was highly significant because the $\mathrm{R}^{2}$ coefficient ranged between 0.97 and 0.99 . This can be described best by the linear regression model. The directional coefficient in the regression equations allowed a direct assessment of the effect of changing the height of the stubble by one unit to the change in the AHI parameter. The intercept reflected the harvest index (HI) value when cutting at the ground level (zero). Depending on the factors tested, at this height $\mathrm{HI}$ ranged from 0.35 (Fig. 5A) up to 0.43 in the vegetative season 2012/2013 (Fig. 5C).

The analysis of the linear regression models shows that an increase in the height of the stubble of WOR of $10 \mathrm{~cm}$ contributed to AHI improvement from 0.012 (in Prusy, for plant categories: medium and large) to up to 0.015 (for plant category: small), which is equal to 2.7 and $3.5 \%$, respectively (Table 4). All the models exhibited a high correlation with the actual data, as evidenced not only by the scatter plots and the estimated $\mathrm{R}^{2}$ coefficient (Fig. 5), but also by the standard errors of regression coefficients and the resulting t-student statistics (Table 4).

Table 5 presents the estimated biomass of the stubble for a range of cutting heights from 10 to $60 \mathrm{~cm}$, since the harvest of WOR at a ground level $(0 \mathrm{~cm})$ is not feasible. The highest difference in the calculated amount of the stubble biomass in the field occurred in the simulated increase 


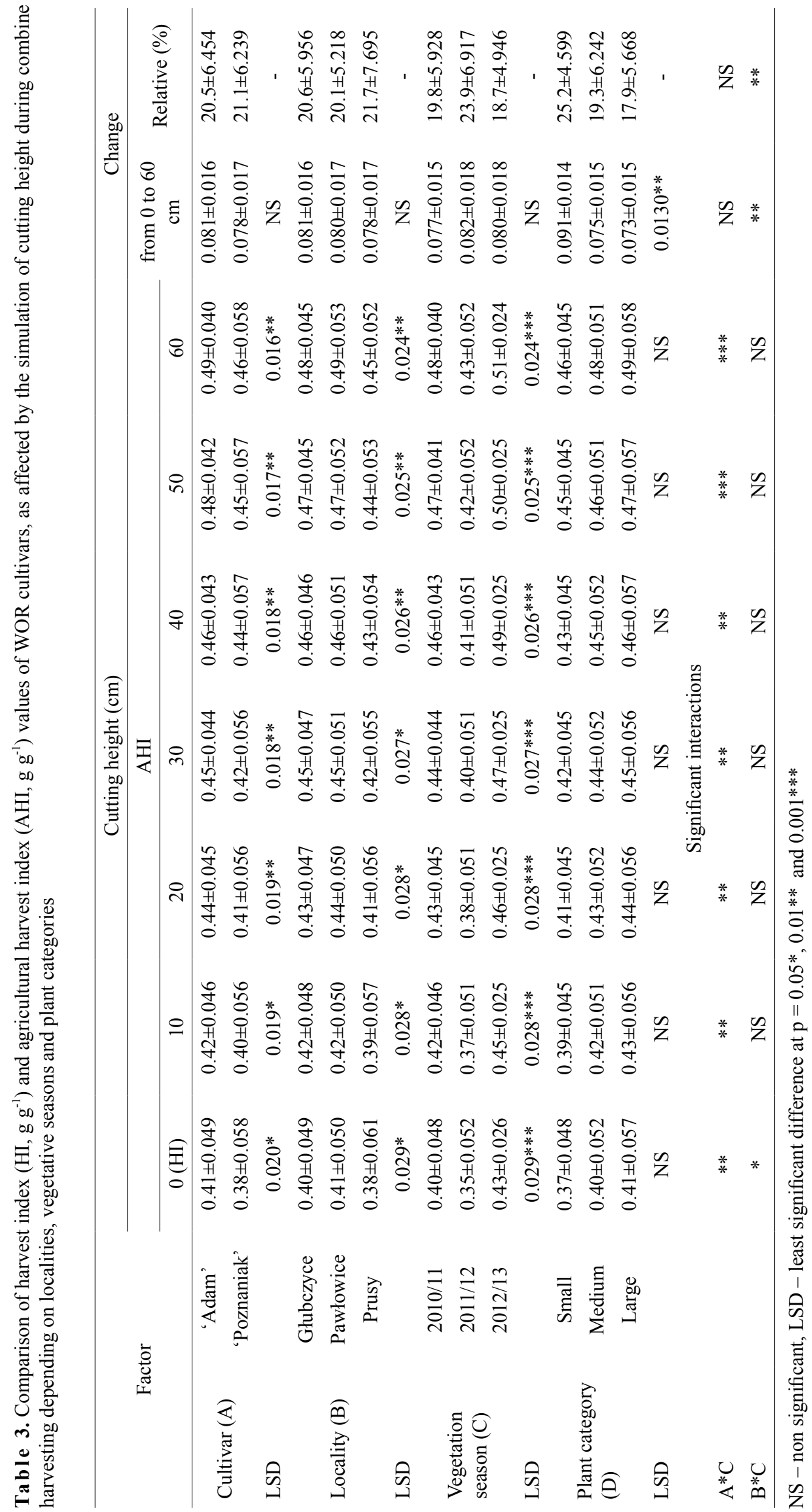



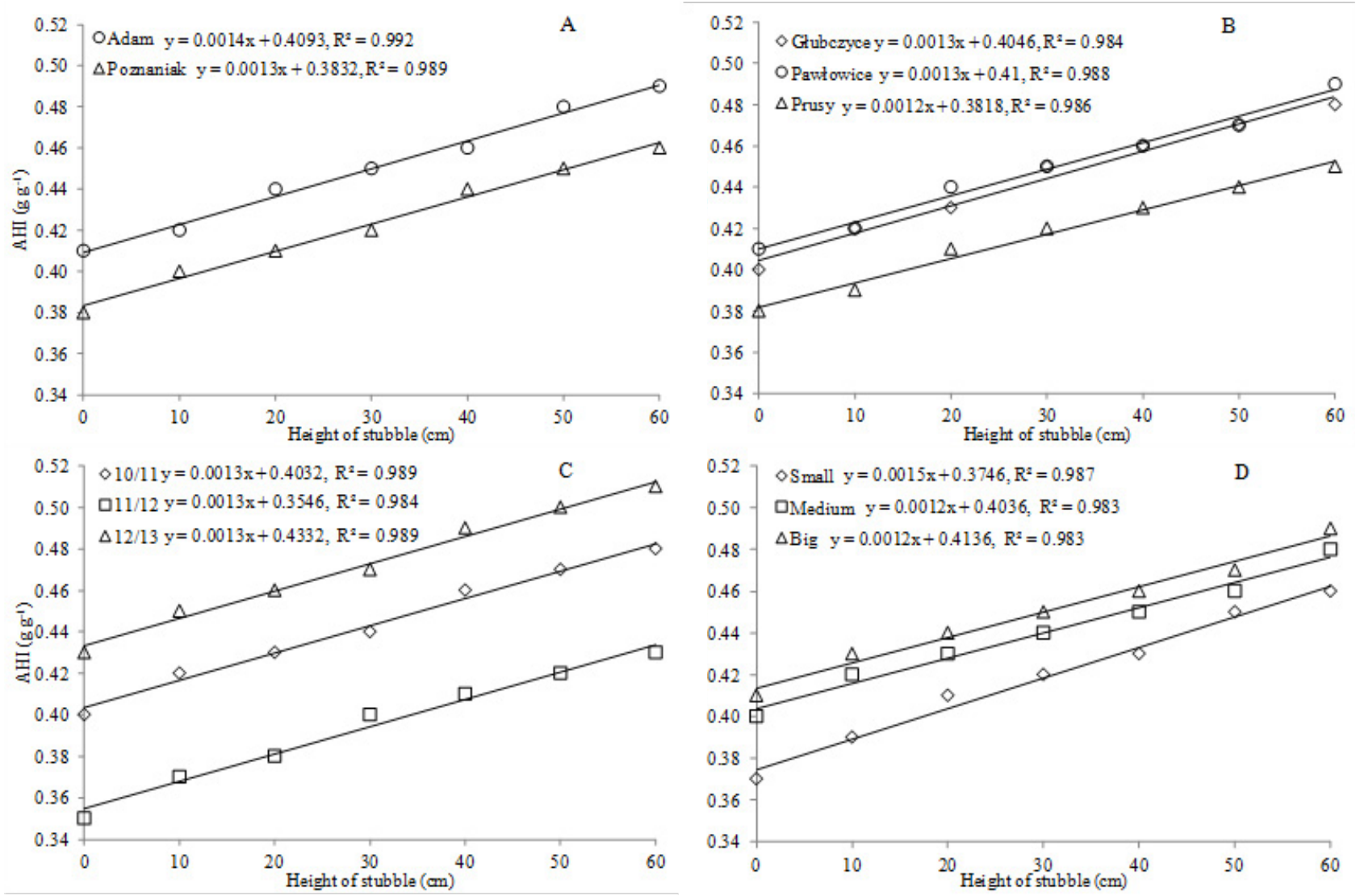

Fig. 5. Relationship between the height of stubble of winter oilseed rape in the range $10-60 \mathrm{~cm}$ and the changes in agriculture harvest index (AHI). A - cultivars, B - locality, C - vegetation seasons, D - plant category.

Tab le 4. Parameters of linear regression models for relationship between cutting height of winter oilseed rape plants and their harvest index (HI) value

\begin{tabular}{|c|c|c|c|c|c|c|c|}
\hline & ctor & $\begin{array}{l}\text { Regression } \\
\text { coefficient }\end{array}$ & $\begin{array}{c}\text { Intercept } \\
\alpha\end{array}$ & $\begin{array}{c}\text { Standard } \\
\text { error }\end{array}$ & $\begin{array}{l}\text { Standard } \\
\text { error }\end{array}$ & $\begin{array}{c}\mathrm{t} \text {-statistic } \\
\beta(5)\end{array}$ & $\begin{array}{c}\text { t-statistic } \\
\alpha(5)\end{array}$ \\
\hline Cultivar (A) & 'Adam' & 0.0014 & 0.41 & 0.000055 & 0.001995 & 24.5 & 205.2 \\
\hline Curtival (A) & 'Poznaniak' & 0.0013 & 0.38 & 0.000062 & 0.002230 & 21.3 & 171.8 \\
\hline & Głubczyce & 0.0013 & 0.40 & 0.000077 & 0.002762 & 17.2 & 146.5 \\
\hline Locality (B) & Pawłowice & 0.0013 & 0.41 & 0.000064 & 0.002304 & 20.1 & 178.0 \\
\hline & Prusy & 0.0012 & 0.38 & 0.000062 & 0.002230 & 19.0 & 171.2 \\
\hline & $2010 / 11$ & 0.0013 & 0.40 & 0.000062 & 0.002230 & 21.3 & 180.8 \\
\hline Vegetative & $2011 / 12$ & 0.0013 & 0.35 & 0.000077 & 0.002762 & 17.2 & 128.4 \\
\hline & $2012 / 13$ & 0.0013 & 0.43 & 0.000062 & 0.002230 & 21.3 & 194.3 \\
\hline & Small & 0.0015 & 0.37 & 0.000077 & 0.002762 & 19.0 & 135.6 \\
\hline $\begin{array}{l}\text { Plant } \\
\text { category (D) }\end{array}$ & Medium & 0.0012 & 0.40 & 0.000071 & 0.002575 & 17.1 & 156.7 \\
\hline & Large & 0.0012 & 0.41 & 0.000071 & 0.002575 & 17.1 & 160.6 \\
\hline
\end{tabular}

in the stubble height from: 10 to 20 , and 50 to $60 \mathrm{~cm}$. Significant differences in the calculated amount of the stubble biomass in the field occurred only for the optimal vegetative season 2011/2012 when the calculated mass of the stubble was the highest (Table 5).

\section{DISCUSSION}

Nowadays, yields of the seeds of winter oilseed rape (WOR) are estimated to increase from decade to decade (Rondanini et al., 2012; Zając et al., 2016). WOR hybrid cultivars produce high yields, sometimes several times 
Table 5. The calculated amount of biomass $\left(\mathrm{Mg} \mathrm{ha}^{-1}\right)$ of winter oilseed rape treated as a stubble depending on the cutting height of plants during the combine harvest, cultivar, locality, and a vegetative season

\begin{tabular}{|c|c|c|c|c|c|c|c|c|}
\hline \multirow{2}{*}{ Factor } & & \multicolumn{6}{|c|}{ Cutting height $(\mathrm{cm})$} & \multirow{2}{*}{$\begin{array}{c}\text { Change } \\
\text { from } 10 \text { to } 60 \mathrm{~cm}\end{array}$} \\
\hline & & 10 & 20 & 30 & 40 & 50 & 60 & \\
\hline \multirow{2}{*}{$\begin{array}{l}\text { Cultivar } \\
\text { (A) }\end{array}$} & Adam & 0.494 & 0.827 & 1.119 & 1.381 & 1.614 & 1.974 & 1.480 \\
\hline & Poznaniak & 0.535 & 0.899 & 1.212 & 1.494 & 1.741 & 2.131 & 1.596 \\
\hline LSD & & NS & NS & NS & NS & NS & NS & NS \\
\hline \multirow{3}{*}{$\begin{array}{l}\text { Locality } \\
\text { (B) }\end{array}$} & Głubczyce & 0.571 & 0.981 & 1.343 & 1.669 & 1.963 & 2.321 & 1.750 \\
\hline & Pawłowice & 0.471 & 0.813 & 1.111 & 1.380 & 1.618 & 1.974 & 1.503 \\
\hline & Prusy & 0.500 & 0.795 & 1.042 & 1.264 & 1.452 & 1.862 & 1.362 \\
\hline LSD & & NS & NS & NS & NS & NS & NS & NS \\
\hline \multirow{3}{*}{$\begin{array}{l}\text { Vegetative } \\
\text { season }(\mathrm{C})\end{array}$} & $2010 / 11$ & 0.423 & 0.733 & 0.998 & 1.230 & 1.428 & 1.811 & 1.388 \\
\hline & $2011 / 12$ & 0.735 & 1.188 & 1.582 & 1.935 & 2.250 & 2.668 & 1.934 \\
\hline & $2012 / 13$ & 0.385 & 0.669 & 0.916 & 1.149 & 1.355 & 1.678 & 1.293 \\
\hline LSD & & $0.1647 * * *$ & $0.2689 * * *$ & $0.3652 * * *$ & $0.4490 * * *$ & $0.5384 * * *$ & $0.5801 * * *$ & $0.4349 * *$ \\
\hline \multicolumn{9}{|c|}{ Significant interactions } \\
\hline $\mathrm{B} \times \mathrm{C}$ & & NS & NS & NS & NS & NS & $*$ & $*$ \\
\hline
\end{tabular}

NS - non significant, LSD - least significant difference at $\mathrm{p}=0.05^{*}, 0.01^{* *}$ and $0.001 * * *$.

higher than currently recorded. The significant difference between the yielding of WOR under the conditions of agricultural practice and that of the experimental conditions shows the plasticity of the cultivars of WOR (Gomez and Miralles, 2011; Takashima et al., 2013). It is emphasized that the main factors currently shaping the yields of WOR seeds in Poland include the weather course, crop position in crop-rotation, nitrogen fertilization, plant protection intensity and cultivar selection (Jankowski et al., 2016; Kotecki et al., 2004; Rathke et al., 2005). Poland is also characterized by strong fluctuations in WOR crop yields over the years, which is a result of unstable agro-climatic conditions (Berry and Spink, 2006).

In the present study, both the hybrid cultivars of WOR yielded a high dry mass of the aboveground parts. The environmental conditions of the locality proved to be a factor that strongly changed the productivity of the WOR cultivars grown under the conditions occurring in Southern Poland. Seyis et al. (2006) highlight the variability of WOR yields in different locations, as a result of genotypic and environmental responses. In the locality of Glubczyce, the yield of WOR was the highest, and resulted from favorable agro-climatic conditions. The biomass yield of $1525 \mathrm{~g} \mathrm{~m}^{-2}$ should be assessed as high for the Central European conditions. Under the optimal hydrothermal conditions of the vegetative season 2011/12, a single WOR plant yielded the highest dry mass, oscillating around $70 \mathrm{~g}$. In that season, the WOR plants developed a higher mass in the lower parts of the main stems $(0-60 \mathrm{~cm})$. This shows that in the vegetative seasons which favor an increased plant productivity
WOR can accelerate the vegetative mass faster than the seed mass, resulting in a lower harvest index (HI). In 2-year experiments performed under good agro-climatic conditions in the Netherlands, Habekotte (1997) obtained yields of the dry mass of the aboveground parts of the WOR $c v$. 'Jet Neuf' in the range of $906-1818 \mathrm{~g} \mathrm{~m}^{-2}$, and the differentiating factors were the locality and vegetative seasons. Behrens and Diepenbrock (2006) also reported weather conditions as a strong determinant of the productivity of the WOR $c v$. 'Lirajet', as the dry yield on the 320th day of full maturity was $9 \mathrm{t} \mathrm{ha}^{-1}$ in 2003, while in the wet season of 2004 it was of $21 \mathrm{tha}^{-1}$. Jankowski et al. (2016) showed that the vegetative seasons had the greatest impact on the HI of WOR which in the 2008/9, 2009/10 and 2010/11 vegetative seasons were of $0.346,0.417$ and 0.334 , respectively. Certain analogies can be traced to nitrogen efficiency, being the most important nutrient for WOR. Several studies have demonstrated that WOR, in response to high nitrogen doses of $>200 \mathrm{~kg} \mathrm{~N} \mathrm{ha}^{-1}$, results in decreased HI values (Rathke et al., 2005; Schulte aufm Erley et al., 2011; Taheri et al., 2012). A similar trend was not confirmed by Jankowski et al. (2016) who, when fertilizing 120, 180 and $240 \mathrm{~kg} \mathrm{~N}$ $\mathrm{ha}^{-1}$, achieved the HI of $0.356,0.368$ and 0.373 , respectively, and the observed differences changed to a lesser extent than those caused by weather conditions.

Changes in the productivity of a single WOR plant are simultaneously affected by the decreasing seed density per square meter, as well as the agriculturally useful features of the long stem hybrids (Behrens and Diepenbrock, 2006; Jankowski et al., 2016; Müller et al., 2008; Śmiatacz, 
2013). In our study, the height of the WOR hybrids under the conditions occurring in Southern Poland did not differ significantly and oscillated around $144 \mathrm{~cm}$; the plants were lower than the WOR plants in China (Yuan and Guan, 1998) but higher than those grown in the arid region of Iran (Miri, 2007). At the same time, Kotecki et al. (2004) showed that higher WOR plants do not develop a high number of lateral branches. In their study, in two successive vegetative seasons (2002/3 and 2003/4) the plant height was 147 and $105 \mathrm{~cm}$, and the number of lateral branches from a single WOR plant was 4.3 and 7.9, respectively (Kotecki et al., 2004).

The interest in the harvest index (HI) of WOR plants is vital, so many authors give this value in their works. However, the observation of the production fields in Poland after the harvest of WOR shows that the height of the stubble is differentiated, but generally high. This observation leads to the questions about the consequences and significance of this fact for the accuracy of the HI value given in literature, as well as the mass of the stubble. That was also a contribution to the new definition of the agricultural harvest index, which takes into account changes in the ratio of the seed weight to the total plant weight, excluding stubble biomass. The stubble does not have any contribution to the yield of WOR seeds, but the thick and low stubble can slow down the harvest, which generates an increase in costs. In order to better understand the harvesting conditions, we measured the mass and diameter of the lower $10 \mathrm{~cm}$ segments of the main WOR stem, to show the differences during the harvest of WOR. Among the studied cultivars, $c v$. 'Poznaniak' had a higher mass of the 10-centimeters segments of the main stem, compared to $c v$. 'Adam'. In turn, the plants of $c v$. 'Adam' were slightly higher than $c v$. 'Poznaniak', but had a lower mass of the aboveground parts. That determined a simultaneously higher HI (0.41) of the $c v$. 'Adam', estimated from the ground level $(0 \mathrm{~cm}-$ control $)$, against $\mathrm{HI}$ $=0.38$ for the $c v$. 'Poznaniak'. The approximate HI values $(0.38-0.40)$ for WOR plants were obtained in the previous studies by Sieling and Kage (2008), but these should be approached with some caution, since the height of the plant cutting was unknown.

In the present study, the range of AHI comparisons of a single WOR plant has been extended to include the three different crop categories: 'large', 'medium' and 'small', which should be considered important cognitive novum. The results clearly show that the higher cutting of the stubble of WOR yields a significant increase in the AHI value, of $c a$. $20 \%$. Ceasing on cutting the WOR plants at a height of $10 \mathrm{~cm}$ and raising the cutting height to $60 \mathrm{~cm}$ changed most preferably the AHI of plants of the 'small' category (with 1-4 lateral branches) by about $0.091 \mathrm{~g} \mathrm{~g}^{-1}$. On the other hand, the change in the AHI values of both the 'medium' and 'large plant' categories were weaker, amounting to $0.07 \mathrm{~g} \mathrm{~g}^{-1}$. The differences in AHI among the plant categories, distinguished on the basis of the number of lateral branches, could be due to the seed mass produced by particular plants. As was shown by Tuncturk and Ciftci (2007), the seed mass of WOR is strongly correlated with the number of branches, which is why the changes in the AHI values were mitigated by the stronger plant branching.

In summary, our studies have shown that it is possible to modify the AHI value by increasing the height of the stubble of WOR plants, and that this relationship is linear and of a high correlation coefficient.

\section{CONCLUSIONS}

1. To include the real conditions occurring during the combine harvest of winter oilseed rape, we propose a new parameter, namely the agricultural harvest index. Agricultural harvest index includes changes in the seeds to plant biomass ratio, resulting from a different height of the stubble.

2. The agricultural harvest index value increases most intensively with an increase in the stubble for plants that have only 1 to 4 lateral branches.

3. In a situation when plants of this kind dominate in the winter oilseed rape canopy, for example, as a result of an improper planting density, it may lead to disturbed results.

4. An increase in the height of the stubble of winter oilseed rape by $10 \mathrm{~cm}$ contributes to the improvement in agricultural harvest index in the range from 0.012 to $0.015 \mathrm{~g} \mathrm{~g}^{-1}$.

5. Increasing the height of the stubble from 10 to $60 \mathrm{~cm}$ leads to an increase in the stubble biomass by about $1.5 \mathrm{Mg}$ $\mathrm{ha}^{-1}(400 \%)$.

Conflict of interest: The Authors do not declare conflict of interest.

\section{REFERENCES}

Acquaah G., 2005. Plant Growth and Development 123-142. In: Principles of Crop Production, Theory, Techniques, and Technology Ed. Pearson Education Inc., New Jersey.

Behrens T. and Diepenbrock W., 2006. Using digital image analysis to describe canopies of winter oilseed rape (Brassica napus L.) during vegetative developmental stages. J. Agronomy Crop Sci., 192(4), 295-302, https://doi. org/10.1111/j.1439-037X.2006.00211.x

Berry P.M. and Spink J.H., 2006. A physiological analysis of oilseed rape yields: past and future. J. Agric. Sci., 144(5), 381-392, https://doi.org/10.1017/S0021859606006423

Chavent G., 1979. Identification of distributed parameter systems: about the output least square method, its implementation and identifiability. Proc. 5th IFAC Symp. Identification and System Parameter Estimation, 1, 85-97, https://doi.org/10.1016/S1474-6670(17)65413-2

Donald C.M. and Hamblin J., 1976. The biological yield and harvest index of cereals as agronomic and plant breeding criteria. Advances in Agronomy, 28: 361-405, https://doi. org/10.1016/S0065-2113(08)60559-3 
Dzieżyc H., Chmura K., and Piotrowski M., 2013. Influence of meteorological conditions on the yield of winter oilseed rape in Lower Silesia. Annals of Warsaw University of Life Sciences - SGGW, Land Reclamation, 45(2): 325-242, https://doi.org/10.2478/sggw-2013-0020

FAOSTAT, 2016. Food and Agriculture Organization of the United Nations statistics. http://faostat.fao.org/ (verified 12 November 2016)

Ghassemi-Golezani K., Khomari S., Dalil B., HosseinzadehMahootchy A., and Chadordooz-Jeddi A., 2010. Effects of seed aging on field performance of winter oilseed rape. J. Food, Agric. Environ., 8(1), 175-178.

Gomez N.V. and Miralles D.J., 2011. Factors that modify early and late reproductive phases in oilseed rape (Brassica napus L.): its impact on seed yield and oil content. Industrial Crops and Products, 34(2), 1277-1285, https://doi. org/10.1016/j.indcrop.2010.07.013

Greef J.M., Hansen F., Pasda G., and Diepenbrock W., 1993. Die Strahlungs-, Energie- und Kohlenstoffbindung landwirtschaftlicher Kulturpflanzen - Ergebnisse und Modellrechnungen. Ber. Landw., 71: 554-566.

Gunasekera C.P., Martin L.D., Siddique K.H.M., Walton G.H., 2006. Genotype by environment interactions of Indian mustard (Brassica juncea L.) and canola (B. napus L.) in Mediterranean-type environments. European J. Agronomy, 25: 1-12, https://doi.org/10.1016/j. eja.2006.02.001

Habekotte B., 1997. Options for increasing seed yield of winter oilseed rape (Brassica napus L.): a simulation study. Field Crops Research 54: 109-126, https://doi.org/10.1016/ S0378-4290(97)00041-5

Hay R.K.M., 1995. Harvest index: a review of its use in plant breeding and crop physiology. Annals of Applied Biology, 126(1), 197-216, https://doi.org/10.1111/j.1744-7348.1995. tb05015.x

Huehn M., 1993. Harvest index versus grain/straw ratio. Theoretical comments and experimental results on the comparison of variation. Euphytica, 68: 27-32, https://doi. org/10.1007/BF00024151

Jankowski K.J. Budzyński W.S., Załuski D., Hulanicki P.S., and Dubis B., 2016. Using a fractional factorial design to evaluate the effect of the intensity of agronomic practices on the yield of different winter oilseed rape morphotypes. Field Crops Res., 188: 50-61, https://doi.org/10.1016/j. fcr.2016.01.007

Kazemeini S.A., Hamzehzarghani H., and Edalat M., 2010. The impact of nitrogen and organic matter on winter canola seed yield and yield components. AJCS, 4(5): 335-342.

Koeslin-Findeklee F. and Horst W.J., 2016. Contribution of nitrogen uptake and retranslocation during reproductive growth to the nitrogen efficiency of winter oilseed-rape cultivars (Brassica napus L.) differing in leaf senescence. Agronomy, 6(1): 2-18, https://doi.org/10.3390/ agronomy6010001

Kotecki A., Kozak M., and Malarz W., 2004. The effect of different crop production systems on growth and yielding of winter rape cultivars. Rośliny Oleiste-Oilseed Crops, 25(1), 97-107.

Kuai J., Sun Y., Zuo Q., Huang H., Liao Q., Wu C., Lu J., Wu J., and Zhou G., 2015. The yield of mechanically harvest- ed rapeseed (Brassica napus L.) can be increased by optimum plant density and row spacing. Scientific Reports 5: 1-14,5 https://doi.org/10.1038/srep18835

Luo X., Ma C., Yue Y., Hu K., Li Y., Duan Z., Wu M., Tu J., Shen J., Yi B., and Fu T., 2015. Unravelling the complex trait of harvest index in rapeseed (Brassica napus L.) with association mapping. BMC Genomics 16:379-389, https:// doi.org/10.1186/s12864-015-1607-0

Mazhari Mousavi S. M., Hosseini S. Z., Resalati H., Mahdavi S., and Garmaroody E.R., 2013. Papermaking potential of rapeseed straw, a new agricultural-based fiber source. J. Cleaner Production, 52: 420-424, https://doi.org/10.1016/j. jclepro.2013.02.016

Miri H.R., 2007. Morphophysiological basis of variation in rapeseed (Brassica napus L.) yield. Int. J. Agric. Biol., 9(5): 701-706.

Müller K., Böttcher U., Meyer-Schatz F., and Kage H., 2008. Analysis of vegetation indices derived from hyperspectral reflection measurements for estimating crop canopy parameters of oilseed rape (Brassica napus L.). Biosystems Eng., 101(2), 172-182, https://doi.org/10.1016/j.biosystemseng. 2008.07.004

Özer H., Oral E., and Dogru Ü., 1999. Relationships between yield and yield components on currently improved spring rapeseed cultivars. Turkish J. Agric. Forestry, 23: 603-607.

Peltonen-Sainio P., and Jauhiainen L., 2008. Association of growth dynamics, yield components and seed quality in long-term trials covering rapeseed cultivation history at high latitudes. Field Crops Res., 108: 101-108, https://doi. org/10.1016/j.fcr.2008.04.006

Rad A.H.S., Abbasian A., and Aminpanah H., 2014. Seed and oil yields of rapeseed (Brassica napus L.) cultivars under irrigated and non-irrigated conditions. J. Animal Plant Sci., 24(1): 204-210.

Rathke G.-W., Christen O., and Diepenbrock W., 2005. Effects of nitrogen source and rate on productivity and quality of winter oilseed rape (Brassica napus L.) grown in different crop rotations. Field Crops Res., 94: 103-113, https://doi. org/10.1016/j.fcr.2004.11.010

Rondanini D. P., Gomez N. V., Agosti M.B., and Miralles D.J., 2012. Global trends of rapeseed grain yield stability and rapeseed-to-wheat yield ratio in the last four decades. European J. Agron., 37(1), 56-65, https://doi.org/10.1016/j. eja.2011.10.005

Schulte auf ־ Erley G., Behrens T., Ulas A., Wiesler F., and Horst W.J., 2011. Agronomic traits contributing to nitrogen efficiency of winter oilseed rape cultivars. Field Crops Res., 124: 114-123. doi:10.1016/j.fcr.2011.06.009 https:// doi.org/10.1016/j.fcr.2011.06.009

Scott R.K., Stokes D.T., McWilliam S.C., Spink J.H., and Clare R.W., 1999. Yield improvement through canopy management: 313-318. Proc. 10th Int. Rapeseed Congr., Canberra, Australia.

Seyis F., Friedt W., and Luhs W., 2006. Yield of Brassica napus L. hybrids developed using resynthesized rapeseed material sown at different locations. Field Crops Res., 96: 176-180, https://doi.org/10.1016/j.fcr.2005.06.005

Sieling K. and Kage H., 2008. The potential of semi-dwarf oilseed rape genotypes to reduce the risk of $\mathrm{N}$ leaching. J. Agric. Sci., 146(1), 77-84, https://doi.org/10.1017/ S0021859607007472 
Skowera B., Jędrszczyk E., Kopcińska J., Ambroszczyk A.M., and Kolton A., 2014. The effects of hydrothermal conditions during vegetation period on fruit quality of processing tomatoes. Polish J. Environ. Studies, 23(1), 195-202.

Śmiatacz K., 2013. Growth, development and yielding of different types of winter rape cultivar depending on sowing date and rate. PhD. Thesis, University of Life Sciences, Poznań, Poland.

Taheri E., Soleymani A., and Javanmard H.R., 2012. The effect of different nitrogen levels on oil yield and harvest index of two spring rapeseed cultivars in Isfahan region. Int. J. Agric. Crop Sci., 4(20): 1496-1498.

Takashima N.E., Rondanini D.P., Puhl L.E., and Miralles D.J., 2013. Environmental factors affecting yield variability in spring and winter rapeseed genotypes cultivated in the southeastern Argentine Pampas. European J. Agronom., 48: 88-100, https://doi.org/10.1016/j.eja.2013.01.008
Tuncturk M. and Ciftci V., 2007. Relationships between yield and some yield components in rapeseed (Brassica napus ssp. oleifera L.) cultivars by using correlation and path analysis. Pakistan J. Botany, 39(1): 81.

Waalen W., Øvergaard S.I., Åssveen M., Eltun R., and Gusta L.V., 2013. Winter survival of winter rapeseed and winter turnip rapeseed in field trials, as explained by PPLS regression. European J. Agron., 51: 81-90, https://doi. org/10.1016/j.eja.2013.06.004

Witek T., Górski T., Kern H., Żukowski B., Budzyńska K., Filipiak K., ... Strzelec J., 1994. Valorisation of agricultural production area according to Polish municipalities. Supplement A-57, 248, IUNG, Puławy, Poland.

Yuan W. and Guan C., 1998. The variation of harvest index in Chinese oilseed rape. Life Sci. Res., 2(3): 212-219.

Zając T., Klimek-Kopyra A., Oleksy A., Lorenc-Kozik A., and Ratajczak K., 2016. Analysis of yield and plant traits of oilseed rape (Brassica napus L.) cultivated in temperate region in light of the possibilities of sowing in arid areas. Acta Agrobotanica, 69(4), https://doi.org/10.5586/aa.1696 